\title{
Erratum to: Development of a Blast Furnace Model with Thermodynamic Process Depiction by Means of the Rist Operating Diagram
}

\author{
Andreas Spanlang ${ }^{1,2}$, Walter Wukovits ${ }^{2}$, and Bernd Weiss ${ }^{3}$ \\ ${ }^{1} \mathrm{~K} 1-\mathrm{MET} \mathrm{GmbH}$, Linz, Austria \\ ${ }^{2}$ Institute of Chemical Engineering, TU Wien, Vienna, Austria \\ IIron- and Steelmaking Technology and Innovation-Direct Reduction, Primetals Technologies Austria GmbH, \\ Linz, Austria \\ Published online March 30, 2020
}

\section{Erratum to:}

Berg Huettenmaenn Monatsh 2020

https://doi.org/10.1007/s00501-020-00963-6

\begin{abstract}
The provided reference to the original publication, which was the basis for this article, was incomplete. The acknowledgements of this article should be amended as follows: We acknowledge the permission to re-publish a modified version of the original article (Spanlang $A$., Wukovits W., Weiss B., Development of a Blast Furnace Model with Thermodynamic Process Depiction by Means of the Rist Operating Diagram, Chemical Engineering Transactions, 52 (2016), pp 973-978) based on a contribution to the 19th Conference on Process Integration, Modelling and Optimisation for Energy Saving and Pollution Reduction - PRES 2016 (27-31 August, 2016, Prague, Czech Republic).
\end{abstract}

The online version of the original article can be found under https://doi.org/10.1007/s00501-020-00963-6.

Dipl.-Ing. A. Spanlang $(\bowtie)$

K1-MET GmbH,

Stahlstraße 14,

4020 Linz, Austria

andreas.spanlang@k1-met.com 